Coupling social norms and commitments: Testing the underdetected nature of social influence

\title{
1.1 Introduction
}

The onslaught of diverse and pressing environmental problems - from losses of natural habitat, species, and potable water, to a changing climate and a rapidly growing human population - necessitates empirically derived solutions. Because environmental problems chiefly stem from human behavior, environmental psychologists have much to contribute as specialists in the development and assessment of pro-environmental interventions. Nearly four decades of research investigating the factors driving conservation behavior have produced an array of demand management strategies tailored to specific populations and contexts (Schultz, 2014).

Normative information is a long-studied social influence strategy in social and environmental psychology that has been especially successful at promoting conservation behavior (Allcott, 2011; Cialdini, 2003; Fielding, Spinks, McCrea, Stewart, \& Gardener, 2013; Schultz, 2014). Comprised of perceptions of what others do (descriptive norms) and what others approve of (injunctive norms), social norms are persuasive to behavior (Cialdini, Reno, \& Kallgren, 1990; Schultz, Nolan, Cialdini, Goldstein, \& Griskevicius, 2007; for a review, see Cialdini \& Goldstein, 2004). Because witnessing others' conduct is thought to convey the likely social rules of a given context, descriptive normative cues allow one to easily engage in appropriate behavior, without deliberation and the associated cognitive expense (Cialdini, 2001). As behavior is undertaken by an increasing number of others, it is progressively perceived as correct (Asch, 1951; Milgram, Bickman, \& Berkowitz, 1969). However, communicating social norms does not require the presence of others (Keizer, Lindenberg, \& Steg, 2008). Non-social information, such as residual behavioral cues like trails through natural lands (Winter, 2006) or 
written communications highlighting what most others do (Schultz, Khazian, \& Zaleski, 2008) can effectively cue normative perceptions and influence behavior.

While normative information is clearly influential, its influence on behavior is often underestimated (Nolan, Kenefick, \& Schultz, 2011). Individuals tend to have asymmetric perceptions of social influence: while others are believed to be susceptible to conformity, people view themselves as less prone to normative influence and see their behavior as less conforming (Pronin, Berger, \& Molouki, 2007). While the behavioral evidence of others' conformity is indicative of social influence, the same behavioral evidence of one's own conformity is overshadowed by introspective explanations; such introspection leads one to justify their behavior for reasons outside of social influence. Nolan, Schultz, Cialdini, Goldstein, and Griskevicius (2008) found that, while others' engagement in energy conservation was rated as the least important reason for reducing energy use, normative beliefs about energy conservation were the strongest predictor of energy use. Additionally, when a normative message was compared to several standard communications, it was rated as the least motivating communication. In actuality, it was the most effective in reducing electricity use. Nolan and colleagues (2008) interpreted this finding as evidence for the underdetected nature of social normative influence. However, an alternative interpretation of the findings exists: it may be that normative influence is simply underreported. Individuals may recognize the pressure from others' behavior, yet, choose not to report it as influential. This is a concern particularly in individualistic societies that tend to have more negative perceptions of conformity, seeing it as allowing the group to control an individual and a loss of one's autonomy (Kim \& Markus, 1999). While Nolan and colleagues (2008) provide theoretical reasoning for the claim that normative 
influence is underdetected and not underreported, here we provide a new empirical test of the nature of normative influence.

\subsection{Literature Review}

If normative influence is truly underdetected, then it should produce a behavioral response that is not perceived to be externally motivated. Alternatively, if normative influence is detected and is simply underreported, then it should be perceived as an external motivator.

Commitment theory serves as a useful model to test whether normative information is interpreted as an internal or external motivator. A synthesis of effects from commitment-making interventions indicates that commitments have moderate and reliable immediate $(r=.27)$ and longer-term $(r=.18)$ effects, and compared to other pro-environmental interventions, commitment-making tends to produce relatively durable changes in behavior (Lokhorst, Werner, Staats, van Dijk, \& Gale, 2013). To begin describing how commitment-making can be used to assess internally and externally motivated messages, the theories and processes thought to underlie the commitment-making effects are described here, with special attention to when a commitment should produce long-term behavior change.

The act of making a commitment (e.g., making a pledge, taking a stance; Joule, Girandola, \& Bernard, 2007) tends to promote behavioral follow-through (Cialdini, 2001; Kiesler, 1971; Lewin, 1947; Lokhorst et al., 2013). Lewin (1947) was the first to examine this effect: proposing that no direct link existed between one's attitudes, beliefs, ideas, and one's behaviors, but that garnering a decision, however, could create that connection. Kiesler (1971) later developed commitment theory, defining the act of making a commitment as an action that pledges or binds an individual to a specific behavior and the degree of commitment as the extent to which one feels bound to the action they committed to. Unless otherwise mentioned, in this 
paper commitment will refer to the act of making a commitment, rather than to the degree to which one is committed to the act. This binding to the action can influence both attitudes and behaviors. In the former, a person who makes a commitment while initially holding nonsupporting attitudes towards that behavior tends to modify his or her attitude to be in-line with the committed behavior. This is supported by Festinger's (1962) consistency model, which predicts that an individual should attempt to resolve discrepant attitudes and behaviors. For those with initially consistent attitudes, a commitment should serve to strengthen the attitude. In either case, a commitment should impact the feelings about the behavior, the beliefs about the behavior, and the pre-disposition to act on the behavior (Kiesler, 1971). A committing act strengthens these three components of an attitude, increasing the likelihood of behavioral followthrough.

Cialdini (2001) similarly proposed that a socialized need for consistency and a change in one's self-concept (one's values, beliefs, and attitudes) drive the behavioral follow-through after making a commitment. The need for consistency is well evidenced in the foot-in-the-door literature, in which after complying with a small request, the likelihood of complying to a greater request increases significantly (Burger, 1999; Freedman \& Fraser, 1966). A commitment can bring one's attention to a behavior, belief, or attitude, and make it salient. Once a commitment is made, the individual tends to act in-line with this behavior thereby fulfilling the need for consistency.

Finally, a commitment also serves to inform one's self-concept, which strengthens the effect of consistency. Self-perception theory proposes that people infer their attitudes, beliefs, and values from their behaviors and the context the behaviors occur in, the same as one uses observation to infer the internal states of others (Bem, 1972). An individual should infer 
attitudes, beliefs, and values that correspond to a commitment they make, so long as the commitment was not made because of an external pressure. When no external justification for the behavior exists, the person should infer that they decided to make a commitment because their own attitudes, beliefs, and/or values support it, shaping one's self-view. This shaping of self-image should in turn motivate future actions, which then help to solidify this new selfconcept. A voluntarily-made commitment fosters a corresponding self-image, and promotes continued behavior change so long as the newly formed self-concept is in place (Cialdini, 2001).

Together, Lewin, Kiesler, and Cialdini all suggest that internalized changes in the individual are needed for a commitment to produce long-term behavioral change, because it is the internalized change that promotes the behavioral follow-through. Importantly, for a commitment to influence one's internal state (e.g., attitude, self-concept), the commitment must be made voluntarily (Cialdini, 2001; Kiesler, 1971). This is in accordance with the theory of cognitive dissonance, which predicts that a behavior will only be perceived as discordant with one's cognitions or previous behavior if the behavior was voluntarily executed. The presence of an external justification allows one to explain behavior outside of one's own beliefs, attitudes, and values (Festinger, 1962). As exemplified in Festinger and Carlsmith's (1959) classic study, enjoyment of the tedious work requested during an experiment was much higher for those receiving $\$ 1.00$, than those receiving $\$ 20.00$. The high incentive to participate in such mindnumbing tasks created an external justification. Without an external justification, individuals only have internal motivation to cite, and tend to see their actions arising from personal motivations or interests.

Kiesler and Sakumura (1966) explain that upon engaging in a commitment act, an individual is to an extent bound to the behavior. Like Festinger and Carlsmith (1959), Kiesler 
and Sakumura (1966) found that greater payment for completing a task produced weaker supporting attitudes for that task compared to participants who received miniscule payment. Similarly, Burger and Caldwell (2003) found the provision of an incentive undermined changes in self-perception, which decreased behavioral follow-through. Taken together, commitmentmaking can lead to sustained behavioral changes, but only when the commitment is made voluntarily. The addition of external pressures produces external justifications, which limit the development of attitudes and a self-concept that supports the behavior, preventing behavioral follow-through.

Because long-term behavioral changes from commitment-making are only evidenced when made under voluntary conditions, pairing a commitment request with a persuasive message can establish whether a message invokes intrinsic or extrinsic motivation. If social norms are underdetected, coupling normative information with a commitment should produce commitments that are perceived as voluntarily made, and thus, produce relatively durable behavior change. Conversely if normative influence is detected and simply underreported, then commitments should be identified as having been made for an external reason and relatively short-term behavior changes should emerge. Because normative information is influential, but we expect that individuals underestimate its influence, it is hypothesized that coupling normative information with commitments will produce relatively long-term conservation. To compare if a commitment made upon receiving a social norm message produces relatively durable change in behavior, the pattern of results was compared to a commitment made upon receiving a strong warning. We hypothesized that a strong warning reminding residents of the penalties associated with violating water restrictions would act as an external motivator and produce short-term water reductions even when a commitment was made. This hypothesis is supported from previous 
research that found warnings about a penalty tend to promote extrinsic motivation, resulting in only a short-term behavior change (Aronson \& Carlsmith, 1963; Deci \& Cascio, 1972). Similarly, Joireman, Posey, Barnes, Truelove, and Parks (2009) found that warnings informing that a shared resource was in jeopardy during a resource dilemma game promoted immediate conservation, but that initial consumption patterns resumed after only a few trials. In comparing commitments made upon receiving a strong warning or normative information, we reasoned that if a commitment made after receiving a social norm produced relatively longer water reductions, it would be evidence that the social norm was not extrinsically motivating (as would be expected if normative information is simply underreported).

In addition to that theoretical question, we also aimed to assess several intervention strategies the state of California was utilizing at the time to promote residential water conservation. While our predictions stem from well-established literature, we see these analyses as critical to providing research specific to water conservation from an applied setting given that policy makers are more likely to trust findings from real-world interventions within a sector of interest (Higgens, 2014). Specifically, we assessed the efficacy of only providing residents with a strong warning. As previously discussed, we expect that a strong warning will invoke external motivation resulting in short-lived changes to behavior. Additionally, an information-only strategy was evaluated to ascertain the effects of simply educating households about water restrictions. Previous research has found that the mere provision of information is generally ineffective at promoting pro-environmental behavior (Bolderdijk, Gorsira, Keizer, \& Steg, 2013; Geller, 1981; Schultz, Messina, Tronu, Limas, Gupta, \& Estrada, 2016; Staats, Wit, \& Midden, 1996; see Abrahamse, Steg, Vlek, \& Rothengatter, 2005 for review in energy domain). As such, it was hypothesized that all treatment groups (excluding households that did not make a 
commitment when given the opportunity) would produce greater immediate water reductions compared to the information-only control condition.

Finally, the commitment-making rate of each strategy was assessed. Both normative information and a strong warning have been found to increase motivation. However, to our knowledge, the motivational strength of the two strategies has not been directly compared. To this end, we explored if one strategy was more effective at garnering commitments.

To test these hypotheses, a 2 (commitment request made: yes or no) X 2 (motivator: social norm or strong warning) plus two control conditions (information-only and no-contact control) experimental design was created and households were randomly assigned to these conditions. For the social norm plus commitment condition and the strong warning plus commitment condition, households had the opportunity to make a commitment (see Figure 1 for graphical depiction of experimental design). Households that made a commitment were the focus of our commitment predictions, however, households that declined to make a commitment were delineated into a separate group and tested in the statistical model.

\section{Method}

We conducted a large-scale field experiment in partnership with a Southern California water utility during California's fourth consecutive year of drought. At the time, an executive order mandating a $25 \%$ statewide urban potable water use reduction had been recently implemented (Executive Order No. B-29-15, 2015). Water districts serving more than 3,000 households were required to achieve specific water reduction targets based on residential water use (California Water Boards, 2015). Along with statewide restrictions, water utilities were also permitted to establish their own urban water use restrictions to aid in reaching the mandated conservation goal. 


\subsection{Participants}

Using an opt-out design, data were collected from 8,876 single-family homes in North County San Diego. While the targeted region spanned multiple cities, the majority resided in the city of Carlsbad. Census data indicated that the population was predominantly White and nonHispanic (74.9\%), followed by Hispanic or Latino (13.3\%), and Asian (7.1\%). The homeownership rate was $64.3 \%$, with the median value of owner-occupied homes at $\$ 614,000$. The median household income level was $\$ 83,908$, and $10.6 \%$ of persons lived below the poverty line (U.S. Census Bureau, 2015).

\subsection{Materials}

The experimental manipulation was delivered via one of five doorhangers (see Figure 2). All doorhangers included the same core information regarding three mandatory water efficiency behaviors:

- Water only twice a week on stipulated days

- Water before 8:00 AM or after 6:00PM

- Water no more than ten minutes per station

In the information-only control condition, the doorhanger included a comprehensive list of water efficiency behaviors. The information-only control condition was based largely on materials already created by the water utility, and reflect the pervasive belief that individuals who know which actions to take to solve an environmental problem will indeed act to mitigate the problem. To address this belief, we created an information-only control condition where households received all the mitigation actions identified by the water utility in efforts of increasing water conservation. In the social norm conditions, residents were informed that over $80 \%$ of households in their community were abiding by the outlined water efficiency guidelines (a 
statistic gathered during a pilot study of residents in the region). Households in the strong warning conditions were reminded of the penalties associated with violating water restrictions, including a $\$ 500$ fine, water service interruption, and prosecution. For households asked to make a commitment, residents were requested to indicate their commitment by checking a box and providing a signature, and then returning the doorhanger to the front door for collection the following day. Each doorhanger was visibly labeled with the household's address in the top right corner.

\subsection{Procedure}

Households were randomly assigned to receive either an information-only, social, norm, or strong warning doorhanger. Roughly half of the households in the latter two conditions were also asked to commit to adhering to the water restrictions (strong warning + commitment; social norm + commitment). With the inclusion of a no-contact control group, households were randomly assigned to one of six conditions. Because not all households in the commitment conditions ultimately made a commitment, those who made a commitment were separated from those who did not make a commitment for statistical analyses. Please see Figure 1 for a graphical depiction.

Trained research assistants distributed the doorhangers, which contained information on opting out of the study, and coded each household's front yard on key characteristics (e.g., green lawn, artificial turf, xeriscaping). Households listed for sale, under construction, part of a homeowner's association, with posted soliciting restrictions, or with residents who refused the doorhanger were excluded from the study. Approximately 24 hours after distribution, research assistants returned to all households in the commitment conditions to retrieve doorhangers. Doorhangers found on the front porch were collected; households were coded as either having 
made the commitment (signed and returned the doorhanger), not making the commitment (doorhanger not returned), or not having received the doorhanger (doorhanger left unsigned on front porch). The doorhangers were distributed over the course of two months; for households included in the final analyses, 46.5\% received a doorhanger in July, 2015, and 53.5\% in August, 2015.

\subsection{Measures}

Water consumption data for each address served as the primary dependent variable and were provided monthly by the water district in hundred cubic feet, which we converted into average gallons per day. The primary dependent variable was obtained at six timepoints: pretreatment month (month -1), intervention month (month 0), and the four subsequent postintervention months (month 1 to month 4). Making a commitment via the experimental doorhanger served as a secondary dependent variable.

\section{Results}

Overall, households used an average of 316.15 gallons per day during the first month of analyses (May); usage increased during the summer months, peaking at 395.26 average gallons per day in August. Water use decreased throughout the fall and winter; during December, the final month of analyses, average water use was 248.88 gallons per day. Data were inspected for outliers by identifying data points three or more times greater than the interquartile range; on average, $1.9 \%$ of households were winsorized at each timepoint (range: $1.7 \%-2.2 \%$ at each timepoint). All identified outliers were winsorized at each timepoint, rather than combined across timepoints. Because the intervention occurred for roughly half of the participants in July, and the remainder in August, cases were centered on the intervention month (month 0). This step ensured that regardless of whether the home received treatment in July or August, the results 
demonstrated the effect over the same timespan (e.g., one month after treatment, four months after treatment) for all households. Recall that household water use was measured at six timepoints (month -1 to month 4); to control for typical household water usage a baseline measurement (water use the month before pre-treatment; month -2) was included as a covariate. Like previous research findings, no difference emerged between the no-contact comparison group and the information-only control group (Schultz et al., 2016). Subsequent analyses evaluated the differences between the treatment groups and the information-only control group. Descriptive statistics relating average water use per condition at each timepoint are provided in Table 1.

\subsection{Landscape characteristics}

Features of the front yard were coded, revealing $11.9 \%$ of landscapes contained exceptionally green lawns, and $15 \%$ appeared to have ceased watering their lawns. Additionally, $17.9 \%$ consisted only of drought resistant plants, while $1.7 \%$ had either artificial turf or no living landscape whatsoever.

\subsection{Commitment rates}

To ascertain the likelihood of making a commitment when a social norm or strong warning was presented, response frequencies were first calculated. For those asked to make a commitment after receiving a normative message, $12.3 \%$ (184) of households did not take the door hanger inside between the distribution and collection date; similarly, $11.8 \%$ (170) of households asked to make a commitment after receiving a strong warning message did not remove the door hanger. Because it was unclear if these households received the experimental manipulation and commitment request, they were removed from subsequent analyses. 
A chi-square test of independence was conducted to determine if households were more likely to make a commitment when presented with a social norm or strong warning message. Households that returned the doorhanger to the front doorstep with a signature were counted as having made a commitment. Households that took the doorhanger inside, but did not return it to the front doorstep for collection the following morning were counted as declining to make a commitment. Upon receiving a normative message, $17.5 \%$ (230) of households made a commitment, whereas upon receiving a strong warning message, 20.9\% (266) of households made a commitment; households were 1.2 times more likely to make a commitment when exposed to a strong warning. While the effect was small, the difference was statistically significant, $\chi^{2}(1, N=2589)=4.71, p=.03$, Cramer's $\left.V=.04\right)$.

Prior research has shown that commitments tend to be made by those already motivated to act (McKenzie-Mohr \& Schultz, 2014). To test this effect, two independent sample t-tests were conducted to determine if pre-existing differences in water consumption during the month preceding the intervention (either May or June, 2015) were evident in households that made a commitment in either commitment conditions. No significant differences were found in average daily gallon consumption between households in the control condition $(M=339.03, S D=$ 214.75) and households that made commitments after receiving normative information $(M=$ $329.39, S D=164.77), t(336.47)=-0.82, p=.41$, mean difference $=9.64,95 \%$ CI $[-32.81,13.55]$; likewise, no pre-existing differences were found between the control and strong warning + commitment condition $(M=340.36, S D=183.88), t(2244)=1.0, p=.92$, mean difference $=1.33,95 \%$ CI $[-25.54,28.22]$.

\subsection{Treatment Effects}


To investigate changes in water consumption between conditions and over time, a repeated measures analysis of covariance (ANCOVA) was conducted. In the commitment conditions, households that made a commitment were separated from those that did not, resulting in seven conditions (shown in Table 1). Mauchly's test indicated the assumption of sphericity had been violated, and Greenhouse Geisser estimates were used. Baseline water use was a significant covariate, $F(1,6829)=11459.87, p<.001$; a main effect of time was found, $F(4.18$, $28556.59)=22.68, p<.001$, and the interaction between time and the covariate was significant, $F(4.18,28556.59)=463.36, p<.001$. No main effect treatment was found, $F(6,6929)=1.64, p$ $=.13$. However, a significant interaction emerged between treatment and time, $F(25.09$, $28556.59)=1.52, p<.05$, and planned comparisons were conducted to investigate if the interaction effects supported the hypotheses.

Our primary hypotheses predicted that, while both commitments made upon receiving normative information or a strong warning should evidence immediate water reductions compared to the information-only control group, only commitments made upon receiving normative information would produce longer-term water reductions. To ascertain if the predicted pattern emerged, two repeated measures ANCOVAs, controlling for baseline water use, were conducted to compare changes in water consumption between pretreatment and the intervention month for each treatment commitment group compared to the control group. Again, baseline water use was a significant covariate $F(1,1655)=3036.14, p<.001$; neither time, $F(1,1655)=$ $1.59, p=.21$, nor intervention group, $F(1,1655)=.09, p=.76$, exerted a significant effect. Significant interactions emerged for both the social norm plus commitment group, $F(1,1655)=$ $7.08, p<.01$, and the strong warning plus commitment group, $F(1,1699)=6.042, p=.01$; these effects translate, respectively, to a $3.5 \%$ and $5.6 \%$ reduction in water consumption compared to 
the control condition during the intervention month. These analyses support the immediate effectiveness of both commitment strategies in reducing household water consumption.

A second series of planned comparison ANCOVAs were conducted to investigate the effect of each commitment strategy on longer-term water reductions. Changes in water consumption between pre-treatment and four months post-intervention (November/December) between both commitment conditions and the control group were analyzed. For the social norm plus commitment group, baseline water use was a significant covariate $F(1,1655)=2242$, $p$ < .001 ; neither time, $F(1,1655)=0.65, p=.80$, nor intervention group, $F(1,1655)=.64, p=.42$, exerted a significant effect. A significant interaction was found; households who made a commitment upon receiving a social norm message evidenced significant water reductions compared to the control condition, $F(1,1655)=9.49, p<.01$; this effect reflects an $8 \%$ reduction in water use four months after the intervention, compared to the control group. This same interaction trend was not evident for households who made a commitment upon receiving a strong warning, $F(1,1689)=.72, p=.39$. Collectively, these results support the prediction that coupling normative information with commitments can lead to long-term behavioral change (see Figure 3 for a graphical representation of planned comparison analyses).

\section{Discussion}

Normative information has been suggested to be an underdetected source of influence on behavior (Nolan et al., 2008; Pronin et al. 2007). We reasoned that if normative influence was truly underdetected, then normative information should not act as an external motivator. To test this, we coupled normative information with a commitment and investigated changes in water use from pre-treatment during the intervention and at a four-month follow-up. Our results showed that the social norm plus commitment (made) households reduced their water 
consumption during both the intervention period, as well as the four-month follow-up. This pattern of results suggests that the normative message did not promote external motivation. If normative influence were simply underreported - a possible explanation for the results reported in Nolan and colleagues (2008) paper - then we would expect normative influence to produce an externally motivated commitment (i.e., individuals detect the influence, but choose not to report it). Here, we do not find evidence of an externally motivated commitment when induced through a social norm message, leading us to support the explanation given by Nolan and colleagues (2008) that normative influence is underdetected.

As a secondary applied goal, the influence of two commonly used intervention strategies on water consumption was assessed. The effectiveness of a strong warning in the commitment procedure was evaluated; this intervention produced immediate reductions in water use, but water use during the four-month follow-up failed to evidence significant differences from the pre-treatment consumption rate. This finding underscores the externally motivating nature of the strong warning intervention, and corroborates the pitfalls of incentive and disincentive strategies identified in the pro-environmental intervention literature (De Oliver, 1999; McKenzie-Mohr \& Schultz, 2014; Schultz; 2014). However, this intervention produced a greater commitmentmaking rate compared to the normative-feedback plus commitment intervention. It may be that a short-term response in a greater number of households could be a more effective strategy than long-term reductions in fewer households. If so, the findings reported here suggest that this would likely be an effective strategy only when a very short-lived behavioral response is necessary, as water use returned to pre-treatment rates by the end of the summer season. Additionally, descriptive statistics (see Table 1) of water use trends for households declining to make a commitment are provided. While not central to our research question, little 
research has evaluated the effect of not making a commitment on subsequent pro-environmental behavior. DeLeon and Fuqua (1995) found no difference between baseline and intervention recycling rates in households declining to make a commitment, suggesting that refusing to make a commitment neither positively nor negatively impacted pro-environmental behavior. During the current study's intervention period, this effect was mirrored by households that did not make a commitment in the strong-warning + commitment condition: water use during both the baseline and intervention period is on par with that of households in the information-only control.

Four months post intervention, however, households in this condition, as well who declined to make a commitment upon receiving a normative information message, used significantly more water than those in the information-only control. It may be that the declining to make a commitment under these circumstances does not produce immediate increases in water use, but leads to increases in the long-term. It is possible to conceive that the households who declined to make a commitment may have psychologically committed to a stance of not caring to reduce water consumption. Upon receiving the request to make a commitment, the action of declining to make a commitment may have solidified this stance. From our procedure, however, it is not clear that all households in this condition truly declined to make a commitment. Recall that households who took the doorhanger inside but did not return it to their front door within 24 hours were coded as "declining to make a commitment". Several alternative explanations exist as to why a resident may not have returned the doorhanger. It could be that residents forgot to return the doorhanger or that the doorhanger was brought inside by someone beside the household decision maker. It could be that the doorhanger was interpreted as an advertisement and ignored outright, or a resident may have entered the house through a garage- or side-door and missed the doorhanger altogether. While we are confident that those who did take the door 
hanger inside and returned it to the front door with a signature made a commitment, it is less clear that those who were coded as "declining" to make the commitment, in fact, committed to not conserving water. Future research could better test this question by allowing households to explicitly choose to decline to make a commitment. Because implications of not making a commitment factor into the efficacy of a commitment-based intervention, commitment research should continue to investigate its effects on subsequent pro-environmental behavior.

The results of the information-only strategy corroborated much of the intervention research (Bolderdijk et al., 2013; Geller, 1981; Schultz et al., 2016; Staats, Wit, \& Midden, 1996): simply communicating an environmental problem and/or solution(s) failed to decrease water consumption. Both commitment groups and the strong warning-only condition used significantly less water during the intervention month compared to the information-only control (see Table 1).

While it is evident that the coupling of a social norm and commitment was more effective than was the coupling of a strong warning and commitment in producing long-term reductions, the study was not able to ascertain if the inclusion of a social norm increased the rate of commitment-making compared to a commitment-only condition. While ample evidence demonstrates that social norms are influential to behavior, future research could investigate the extent to which normative messages are motivational compared to other types of known motivators (e.g., disincentives). In application, it would be meaningful to know whether the inclusion of a normative message increases the likelihood of making a commitment.

Despite this limitation, this study succeeded in developing a deployment method for a commitment intervention that could be readily adopted by municipalities and utilities. Much of the commitment-making literature utilizes face-to-face contact to acquire commitments. Such an 
intervention, while effective, is time-intensive. To reduce this implementation barrier, doorhangers were used to communicate the commitment request. Perceived publicity was increased by personally addressing each doorhanger and by collecting the doorhanger the following day, and the active nature of commitment-making was promoted by requiring residents' signatures. Additionally, a methodological weakness in the commitment-making literature is that many of the commitment requests are preceded by a request to participate in the study and permission to access resource consumption information; such a process leads to a multiple-request paradigm, making it impossible to ascertain if the evidenced effects are due to the commitment manipulation, or a foot-in-the-door effect (Katzev \& Johnson, 1983). Here, an opt-out consent strategy was used, which allowed for the pure assessment of the commitment effect. To our knowledge, this is the first study to employ such a method while assessing the impact of a signature-only commitment request. These methods and findings should prove useful to both academics and applied professionals aiming to implement a scalable intervention.

To our knowledge, only descriptive norms have been tested for an underdetected influence. According to Cialdini (2011), the influence of descriptive and injunctive norms stem from two separate motivational bases. Descriptive norms indicate what others do and are influential because the norm provides quick information about what behavior will likely be effective in a given context. Alternatively, injunctive norms indicate what others approve of and are influential because these norms provide information about what behaviors may result in social acceptance or rejection. The extent to which these separate motivational bases result in differing levels of detecting normative influence seems a fruitful area for future research.

The results from the reported experiment suggest that descriptive social norms do not act as an external motivator, which supports the claim that normative influence is underdetected 
rather than underreported. From an applied perspective, these findings, along with the assessment of several other prominent water conservation strategies should add to the growing body of literature assessing the efficacy of traditionally employed interventions. Environmental psychologists have much to contribute to the assessment and development of demand management strategies in resource conservation, and can aid practitioners in building a portfolio of strategies to mitigate the specific environmental issues they face. 


\section{References}

Abrahamse, W., Steg, L., Vlek, C., \& Rothengatter, T. (2005). A review of intervention studies aimed at household energy conservation. Journal of Environmental Psychology, 25(3), 273-291.

Allcott, H. (2011). Social norms and energy conservation. Journal of Public Economics, 95(9), 1082-1095.

Aronson, E., \& Carlsmith, J. M. (1963). Effect of the severity of threat on the devaluation of forbidden behavior. The Journal of Abnormal and Social Psychology, 66(6), 584-588.

Asch, S. E. (1951). Effects of group pressure upon the modification and distortion of judgments. Groups, Leadership, and Men, 222-236.

Bem, D. J. (1972). Self-perception theory. Advances in Experimental Social Psychology, 6, 1-62.

Bolderdijk, J. M., Gorsira, M., Keizer, K., \& Steg, L. (2013). Values determine the (in)effectiveness of informational interventions in promoting pro-environmental behavior. PLoS ONE, 8(12): e83911.

Burger, J. M. (1999). The foot-in-the-door compliance procedure: A multiple-process analysis and review. Personality and Social Psychology Review, 3(4), 303-325.

Burger, J. M., \& Caldwell, D. F. (2003). The effects of monetary incentives and labeling on the foot-in-the-door effect: Evidence for a self-perception process. Basic and Applied Social Psychology, 25(3), 235-241.

California Water Boards (2015). Fact sheet: Emergency conservation regulation: Implementing $25 \%$ conservation statewide. Sacramento, CA. Retrieved from: 
http://www.waterboards.ca.gov/water_issues/programs/conservation_portal/docs/fact sheet/ implementing_25percent.pdf

Cialdini, R. B. (2001). Influence: Science and practice. Boston: Allyn \& Bacon.

Cialdini, R. B. (2003). Crafting normative messages to protect the environment. Current Directions in Psychological Science, 12(4), 105-109.

Cialdini, R. B. (2011). The focus theory of normative conduct. In Van Lange, P. A. M., Kruglanski, A. A., \& Higgins, E. T. (Eds.), Handbook of theories of social psychology, volume 2 (295-312). London: SAGE

Cialdini, R. B. \& Goldstein, N. J. (2004). Social influence: Compliance and conformity. Annual Reviews of Psychology, 55, 591-621.

Cialdini, R. B., Reno, R. R., \& Kallgren, C. A. (1990). Focus theory of normative conduct: Recycling the concept of norms to reduce littering in public places. Journal of Personality and Social Psychology, 58(6), 1015-1026.

Deci, E. L., \& Cascio, W. F. (1972). Changes in intrinsic motivation as a function of negative feedback and threats. Paper presented at Eastern Psychological Association Meeting, Boston, MA.

DeLeon, I. G. \& Fuqua, R. W. (1995). Effects of public commitment and feedback on curbside recycling. Environment and Behavior, 27(2), 233-250.

De Oliver, M. (1999). Attitudes and inaction: A case study of the manifest demographics of urban water conservation. Environment and Behavior, 31, 372 - 394. 
Executive Order No. B-29-15 (2015). Retrieved from: https://www.gov.ca.gov/docs/4.1.15_ Executive_Order.pdf

Festinger, L. (1962). A theory of cognitive dissonance, volume 2. Redwood City, CA: Stanford University Press.

Festinger, L., \& Carlsmith, J. M. (1959). Cognitive consequences of forced compliance. Journal of Abnormal and Social Psychology, 58(2), 203-210.

Fielding, K. S., Spinks, A., Russell, S., McCrea, R., Stewart, R., \& Gardener, J. (2013). An experimental test of voluntary strategies to promote urban water demand management. Journal of Environmental Management, 114, 343-351.

Freedman, J. L., \& Fraser, S. C. (1966). Compliance without pressure: the foot-in-the-door technique. Journal of Personality and Social Psychology, 4(2), 195-202.

Geller, E. S. (1981). Evaluating energy conservation programs: Is verbal report enough? Journal of Consumer Research, 8(3), 331-335.

Higgens, N. (2014, December). Notes from the U.S. General Services Administration. In C. Jones (Chair), Policy drivers for research into climate and energy, Washington, D.C.

Joireman, J., Posey, D. C., Barnes Truelove, H., Parks, C. D. (2009). The environmentalist who cried drought: Reactions to repeated warnings about depleting resources under conditions of uncertainty. Journal of Environmental Psychology, 29, 181-192.

Joule, R. V., Girandola, F., \& Bernard, F. (2007). How can people be induced to willingly change their behavior? The path from persuasive communication to binding communication. Social and Personality Psychology Compass, 1(1), 493-505. 
Katzev, R. D., \& Johnson, T. R. (1983). A social-psychological analysis of residential electricity consumption: The impact of minimal justification techniques. Journal of Economic Psychology, 3(3), 267-284.

Keizer, K., Lindenberg, S., \& Steg, L. (2008). The spreading of disorder. Science, 322(5908), 1681-1685. doi:10.1126/science. 1161405

Kiesler, C. A. (1971). The psychology of commitment: Experiments linking behavior to belief. New York, NY: Academic Press.

Kiesler, C. A., \& Sakumura, J. (1966). A test of a model for commitment. Journal of Personality and Social Psychology, 3(3), 349.

Kim, H., \& Markus, H. R. (1999). Deviance or uniqueness, harmony or conformity? A cultural analysis. Journal of Personality and Social Psychology, 77(4), 785-400.

Lewin K. (1947). Group decision and social change. In T.M. Newcomb \& E.L. Hartley (Eds.), Readings in social psychology (330-344). New York, NY: Henry Holt and Company.

Lokhorst, A. M., Werner, C., Staats, H., van Dijk, E., \& Gale, J. L. (2013). Commitment and behavior change: a meta-analysis and critical review of commitment-making strategies in environmental research. Environment and Behavior, 45(1), 3-34.

McKenzie-Mohr, D., \& Schultz, P. W. (2014). Choosing effective behavior change tools. Social Marketing Quarterly, 20, 35-46.

Milgram, S., Bickman, L., \& Berkowitz, L. (1969). Note on the drawing power of crowds of different size. Journal of Personality and Social Psychology, 13(2), 79-82. 
Nolan, J. M., Kenefick, J., \& Schultz, P. W. (2011). Normative messages promoting energy conservation will be underestimated by experts ... unless you show them the data. Social Influence, 6(3), 169-180.

Nolan, J. M., Schultz, P. W., Cialdini, R. B., Goldstein, N., \& Griskevicius, V. (2008). Normative influence is underdetected. Personality and Social Psychology, 34(7), 913923.

Pronin, E., Berger, J., \& Molouki, S. (2007). Alone in a crowd of sheep: Asymmetric perceptions of conformity and their roots in an introspection illusion. Journal of Personality and Social Psychology, 92(4), 585-595.

Schultz, P. W. (2014). Strategies for promoting pro-environmental behavior: Lots of tools but few instructions. European Psychologist, 19(2), 107-117.

Schultz, P. W., Khazian, A. M., \& Zaleski, A. C. (2008). Using normative social influence to promote conservation among hotel guests. Social Influence, 3(1), 4-23.

Schultz, P. W., Messina, A., Tronu, G., Limas, E. F., Gupta, R., \& Estrada, M. (2016).

Personalized normative feedback and the moderating role of personal norms: A field experiment to reduce residential water consumption. Environment and Behavior, 48(5), 686-710.

Schultz, W. P., Nolan, J. M., Cialdini, R. B., Goldstein, N. J., \& Griskevicius, V. (2007). The constructive, destructive, and reconstructive power of social norms. Psychological Science, 18, 429-434. 
Staats, H. J., Wit, A. P., \& Midden, C. Y. H. (1996). Communicating the greenhouse effect to the public: Evaluation of a mass media campaign from a social dilemma perspective. Journal of Environmental Management, 46(2), 189-203.

U.S. Census Bureau (2015). QuickFacts: Carlsbad city, California. Retrieved from: http://www.census.gov/quickfacts/table/PST045215/0611194,0653322

Winter, P. L. (2006). The impact of normative message types on off-trail hiking. Journal of Interpretation Research, 11, 35-52. 
Table 1. Average daily water use (gallons) for households across conditions.

\begin{tabular}{|c|c|c|c|c|c|}
\hline \multirow{7}{*}{$\begin{array}{l}\text { Social Norm } \\
N=1375\end{array}$} & & $M$ & $\underline{S D}$ & $\frac{95 \% \mathrm{CI}}{\underline{\text { Lower }}}$ & $\frac{95 \% \mathrm{CI}}{\text { Upper }}$ \\
\hline & Pre-treatment month & 352.33 & 117.40 & 346.13 & 358.54 \\
\hline & Intervention month & 372.90 & 125.82 & 366.25 & 379.55 \\
\hline & Post-month 1 & 383.24 & 142.47 & 375.71 & 390.77 \\
\hline & Post-month 2 & 337.23 & 133.68 & 330.16 & 344.3 \\
\hline & Post-month 3 & 310.69 & 127.22 & 303.96 & 317.41 \\
\hline & Post-month 4 & 274.22 & 124.30 & 267.65 & 280.8 \\
\hline \multirow{6}{*}{$\begin{array}{l}\text { Social Norm }+ \\
\text { Commitment } \\
N=227\end{array}$} & Pre-treatment month & $358.22 *$ & 117.46 & 342.94 & 373.5 \\
\hline & Intervention month & $361.87 *$ & 125.87 & 345.50 & 378.25 \\
\hline & Post-month 1 & 378.04 & 142.51 & 359.49 & 396.58 \\
\hline & Post-month 2 & $324.46^{*}$ & 133.73 & 307.06 & 341.86 \\
\hline & Post-month 3 & 301.21 & 127.28 & 284.65 & 317.77 \\
\hline & Post-month 4 & $249.76^{*}$ & 124.34 & 233.59 & 265.94 \\
\hline \multirow{6}{*}{$\begin{array}{l}\text { Strong Warning } \\
N=1474\end{array}$} & Pre-treatment month & 352.15 & 117.40 & 346.16 & 358.15 \\
\hline & Intervention month & $365.92 *$ & 125.81 & 359.50 & 372.34 \\
\hline & Post-month 1 & 373.53 & 142.44 & 366.25 & 380.8 \\
\hline & Post-month 2 & 332.24 & 133.68 & 325.42 & 339.07 \\
\hline & Post-month 3 & 302.30 & 127.23 & 295.81 & 308.8 \\
\hline & Post-month 4 & 269.78 & 124.28 & 263.44 & 276.13 \\
\hline \multirow{6}{*}{$\begin{array}{l}\text { Strong Warning }+ \\
\text { Commitment } \\
N=261\end{array}$} & Pre-treatment month & 347.20 & 117.42 & 332.96 & 361.45 \\
\hline & Intervention month & $354.98 *$ & 125.80 & 339.72 & 370.25 \\
\hline & Post-month 1 & $368.91 *$ & 142.46 & 351.63 & 386.2 \\
\hline & Post-month 2 & 331.22 & 133.67 & 315.00 & 347.44 \\
\hline & Post-month 3 & $293.75 *$ & 127.22 & 278.31 & 309.18 \\
\hline & Post-month 4 & $261.49 *$ & 124.28 & 246.41 & 276.57 \\
\hline \multirow{6}{*}{$\begin{array}{l}\text { Social Norm }+ \\
\text { Commitment Declined } \\
N=1072\end{array}$} & Pre-treatment month & $359.16^{*}$ & 117.41 & 352.14 & 366.19 \\
\hline & Intervention month & 372.82 & 125.79 & 365.29 & 380.35 \\
\hline & Post-month 1 & 385.27 & 142.46 & 376.74 & 393.8 \\
\hline & Post-month 2 & 340.17 & 133.68 & 332.17 & 348.18 \\
\hline & Post-month 3 & $317.18^{*}$ & 127.23 & 309.57 & 324.8 \\
\hline & Post-month 4 & $276.95 *$ & 124.29 & 269.51 & 284.4 \\
\hline \multirow{5}{*}{$\begin{array}{l}\text { Strong Warning }+ \\
\text { Commitment Declined } \\
N=1004\end{array}$} & Pre-treatment month & 348.32 & 117.40 & 341.05 & 355.58 \\
\hline & Intervention month & $367.71 *$ & 125.79 & 359.92 & 375.49 \\
\hline & Post-month 1 & 376.35 & 142.46 & 367.54 & 385.17 \\
\hline & Post-month 2 & 336.24 & 133.68 & 327.98 & 344.51 \\
\hline & Post-month 3 & 309.77 & 127.22 & 301.89 & 317.64 \\
\hline
\end{tabular}




\begin{tabular}{|c|c|c|c|c|c|}
\hline & Post-month 4 & $279.43^{*}$ & 124.27 & 271.74 & 287.12 \\
\hline \multirow{6}{*}{$\begin{array}{l}\text { Information-only Control } \\
N=1424\end{array}$} & Pre-treatment month & 347.21 & 117.40 & 341.12 & 353.31 \\
\hline & Intervention month & 374.64 & 125.81 & 368.11 & 381.18 \\
\hline & Post-month 1 & 378.83 & 142.45 & 371.43 & 386.23 \\
\hline & Post-month 2 & 336.19 & 133.66 & 329.25 & 343.14 \\
\hline & Post-month 3 & 307.21 & 127.21 & 300.60 & 313.82 \\
\hline & Post-month 4 & 269.75 & 124.30 & 263.30 & 276.21 \\
\hline \multirow{6}{*}{$\begin{array}{l}\text { No-contact Comparison } \\
N=1568\end{array}$} & Pre-treatment month & 351.17 & 117.41 & 345.12 & 356.98 \\
\hline & Intervention month & 369.09 & 125.80 & 362.87 & 375.32 \\
\hline & Post-month 1 & 375.75 & 142.47 & 368.70 & 382.80 \\
\hline & Post-month 2 & 330.58 & 133.68 & 323.96 & 337.19 \\
\hline & Post-month 3 & 303.98 & 127.23 & 297.69 & 310.28 \\
\hline & Post-month 4 & 267.40 & 124.30 & 261.25 & 273.56 \\
\hline
\end{tabular}

Note. Adjusted means in water consumption for each condition across six timepoints; $p<.05$ for 

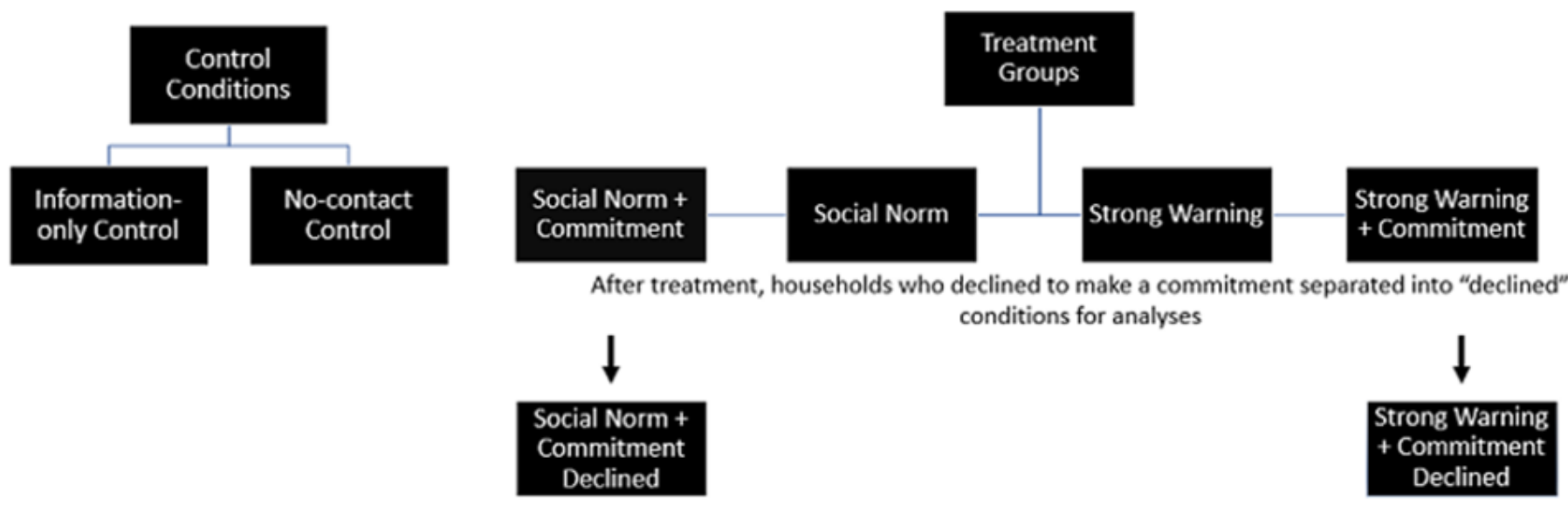

Figure 1. Graphical depiction of the experimental conditions. 


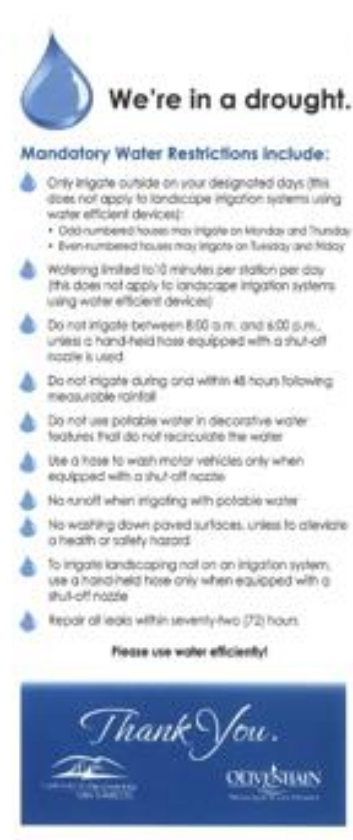

Information only

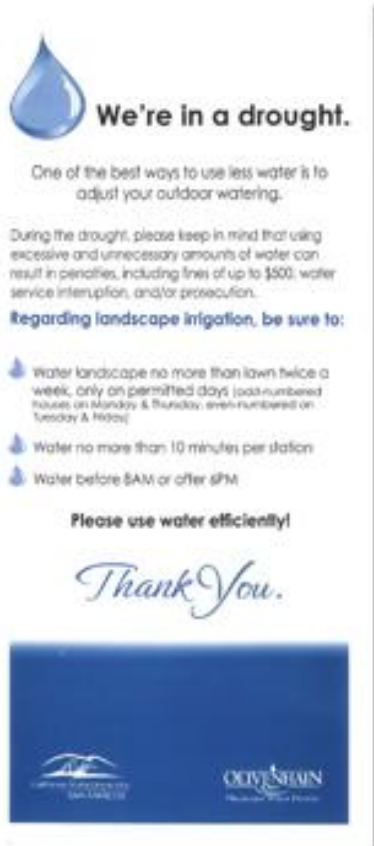

Strong warning

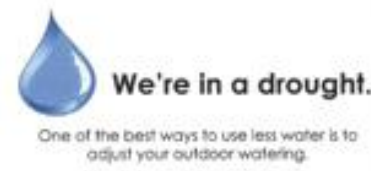

Oung re dougt, phese ceep in mind hat vitro esst n penoter incising amounth of wale con

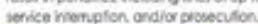

Rogarding landscape imloation be sure to:

4 wote landicope no more than inice a weec.

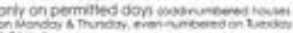

wore no more tron 10 merules der yotion

d. Woter belore seve or ote SPM

Please commit to using water efficiently!

I L tescidert of

cenmin to esccientily waterno my landicape.
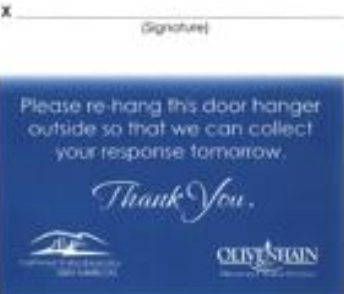

Strong warning + commitment

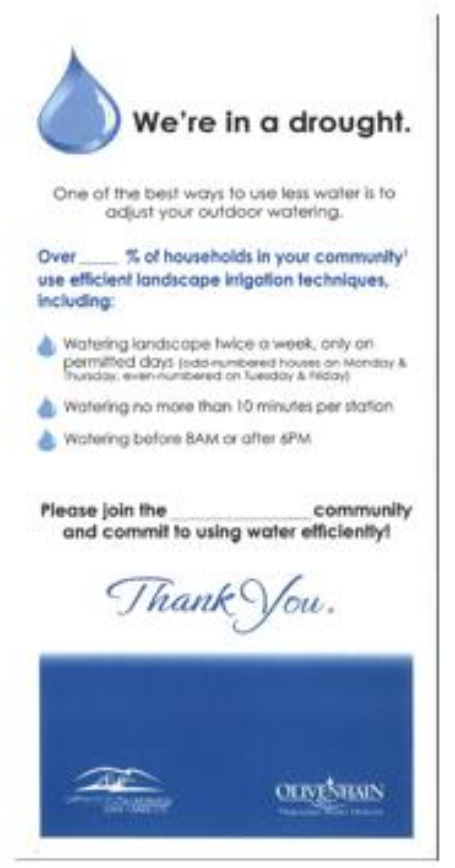

Social norm

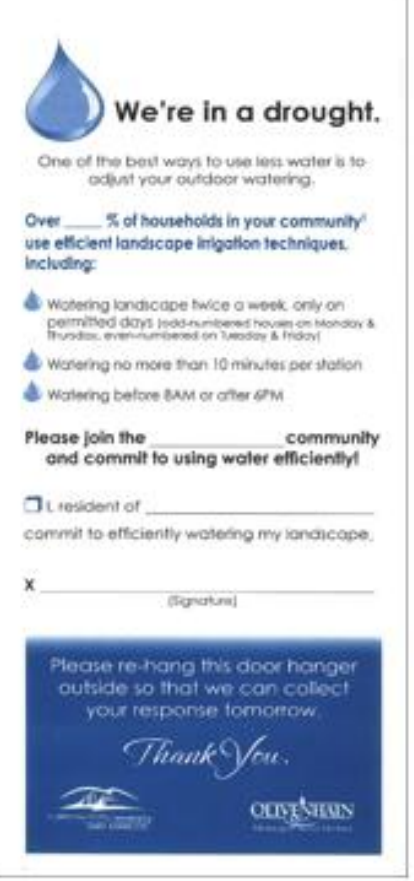

Social norm + commitment

Figure 2. Experimental materials by condition. 


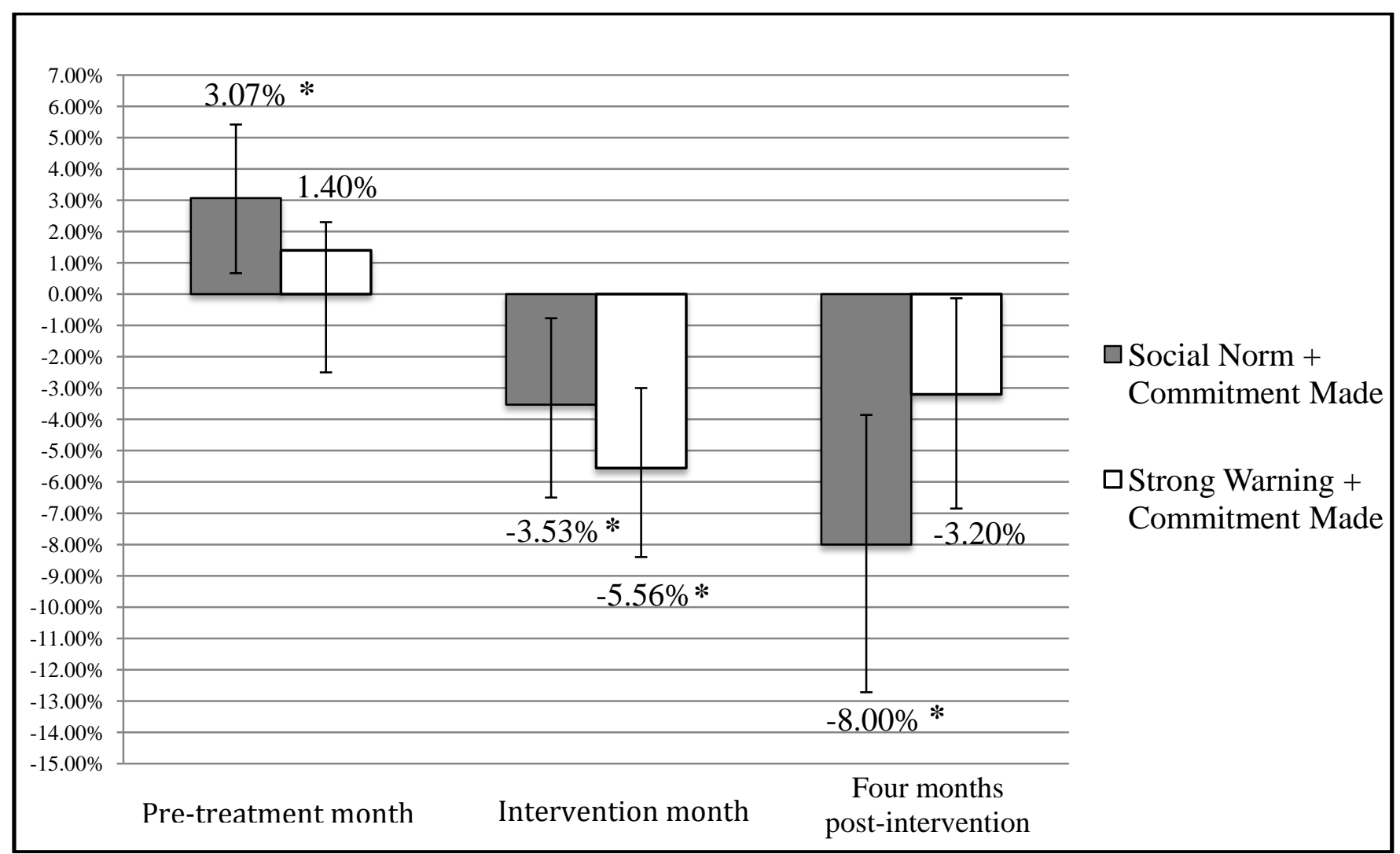

Figure 3. Adjusted mean percent difference in water consumption from control group for each commitment group, across time. Error bars represent 95\% confidence intervals around the adjusted mean differences. 